\title{
Uma raça cromossômica natural de Tityus bahiensis (Scorpiones-Buthidae)
}

\author{
S. de Toledo Pka Jor. \\ Protessor de Zoologia, Anatomia e Fisiologia \\ üu Escolo Superior de Agricultura "Luiz de Queiroz", \\ da Universidade de Såo Paulo
}

\section{INDIC:}

Introduçăo

Material e Métodos

Espermatogónios

Espermatócitos primários .. 186

Cistos tetrapibides 187

Espermat6́citos secundírios 187
Cromossomios somaticos da semea ............... 188 Mecanismo sexo-determi- . nante $\ldots \ldots \ldots \ldots \ldots \ldots, 180$

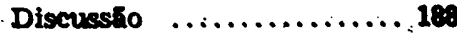

. Summary $\ldots \ldots \ldots \ldots \ldots \ldots 100$

Literatura citada ......... 192 


\section{INTRODUÇAO}

Tityı!s bahiensis, uma das espécies mals comuns de Escorpioes do Brasil, iem sido o objeto de repetidas investigaçóes relativas a morfologia e ao comportamento de seus cromossómios na espermatogènese. Ficou estabelecido, numa série de publicaçסes; aue essa espécie passul apenas 6 cromossomios, fato esse constatado tanto nas células somáticas do embriáo, como nos espermátogónios. (PIZA 1939, 1939a, 1941, 1943, 1943a, 1943b, 1944, 1946). Embora as fibras do fuso se prendam ao longo de todo $:$ corpo dos cromossomios, estes foram considerados como possuindo apenas dols cinetocores, um em cada extremidade, de cuja atuacár resulta a influencia generalizada que faz com que 1) iaparelho acromático se desenvolva. em toda extensáo dos cromossom!cs. Allás, que da atividade de cinetocores localizados ccde se originar um sistema fibrilar completo relacionado com o croniossomio inteiro, ficou magnificamente demonstrado pelo comportamento do cromossomio extranumerário de Narcissus, recentemente estudado por FERNANDES (1946).

Os inconvenientes da dicentricidade dos cromossomios do T'tyus bahiensis foram largamente compensados pelo desenvolvimento te um mecanismo que suprimiu inteiramente a formaçăo de quiasmas e orlenta os bivalentes, sempre formados por dois cromossomios dispostos paralelamente e sem qualquer torcedura de um sobre o outro, de tal modo, que a separaça se processa sem rupturas. Apesar de ser esta a regra, nem porisso deixa de constituir a dicentricidade dos cromossomios ameaça constante para a sua integridade ou para a regularidade do ceu comportamento. Um distúrbio na orientação - e isso deve ser esperado com trequencla num organismo cujos cromossomios căn normalmente dicentricos - fará com que os cromossomiòs passem sem se separar para o mesmo pollo ou formem pontes anafásicas que acabam se fragmentando. As anomalias devides a fragmentaçăo dos cromossomios e à consequente permuta de partes tornam-se porisso comuns nessa éspécie. A raridade $\mathrm{c} \cap \mathrm{m}$ que os fragmentos acentricos (vesiculados fora da área do fuso) ou monocentricos (movendo-se para os polos paralelsmente ao nixo do fuso) têm sido encontrados, fala da ex- 
trema facilidado com que eles se soldam pela superficie de fratura, dando dessa maneira origem aos elementos compostos de partes pertencentes a cromossomios distintos, os quais, nas métálases primárias, dåo. origem as figuras em crua, tantas vezes refarides.

Ao lado de anomallas isoladas, outras foram encontradas em todas as células de um mesmo clsto e bem assim em todos as cistos de um mesmo tésticulo. Neste altimo caso considerouse' a anomalia como exprimindo a condiça "normal" do individuo. I como se verificou, nesta e em outras especies (PIZA 1947, 194'(a), que, qualquer que seja a complicacalo assinalada na metáfase dos espermatócitos primários, estes se dividem em espermatócitos secundários, os quais dăo origem a espematidios que se transformam regularmente em espermatosoides, interessante serie se se pudesse conhecer, sem previa dissecaç5, :2 constituiçăo cromossomica de um desses individuos aberrantes, fazer o seu cruzamento com uma femea de constituigao igualmente connecida, para verfficar, caso a fertllizagío losse viável, qual seria a constituiçăo dos produtos. Tedricamente poderemos imaginar o que acontecerla se um macho portador de qualquer das anomalias encontradas fecundasse uma femea de constitulçăo cromossomica normal.

Agora possuimos interessantes dados que nos provam que as aberrạces cromossomicas devidas a fragmentaça e permuta. de partes, por mais complexas que sejam, nzo so se mostram perfeltamente viáveis, como podem se flxar em estravagantes raças cromossominas.

\section{MATHRIAL E MOTODOS}

Serviu-nos para o presente estudo um pequeno lote de Tityus bahiensis recebido da Fazenda $\mathbf{S}$. Jose, no municipio de S. Jozquim, Estado de $S$. Paulo, representado por 5 machos $e 7$ femeas. Pequena parte do testiculo de 2 machos fol estudada epaceto-orceina e a parte restante, bem como os demais testículos, frram lixados em Allen-Bauer, incluidos em parafina, cortados com 16 micra e coloridos pela hematoxilina de Heldenhain. Os ovariuteros de duas femeas foram examinados em aceto-arcelna e cos das outras 5 em cortes executados segundo o mesmo método usado para os testículos. 


\section{ESPERMATOGONIOS}

Os espermatoginnios săo regularmente providos de 9 cromossom:!s te tamanhos diferentes, havendo 2 malores que os demais. (Fig. 1). Asses cromassomios comportam-se da maneira usual, ivto é movem-se, na ancifase, paralelamente 20 plano do equadar e aprésentam tibras do fuso ao longo de todo o seu comprimento.

\section{ESPERMATOCTTOS PRIMARIOS}

As matáfasns primárias oferecem-nos um aspecto bastante singular: Säo irvarlavelmente formadas por um bivalente llvre e por um complexo representado pelos sete cromossomion restantes, os auals, ao se juntarem, sempre da mesma mane:ra, dấ ol igem a uma .nteressante flgura constitulda por 'duas cruzes reunidas por um braço comum, sendo que uma delas se continua por um. ramo bastante longo, que geralmente se apresenta desvirido par um lado. (Fig. 2). fácll distinguir nesse complezo os sete cromossomios que o constituem. As montagens em orceina acética déo verdadeiros esquemas das relaçós dos e!ementos associados, os quais se apresentam separados por largo espaço. (Figs. 4 e 5). Ve-se, entzo, com clareza, que algurs cromossomios se paream com tres outros. 0 ramo ma:s longo do complexo acha-se nessa situaça. thsse ramo é fo. mario por um extenso cromossomio - provkvelmente. - maior dos elementos assinalados nos espermatogonios - " qual, tepnis de ie ter pareado com dois outros cromossomios do sompjexc, tomando desse modo parte na formaçâo de dois bracos de uma das cruzes, continua-se, por longa extensáo, pareado com um terceiro cromossomio que năo se junta senå : ele, isto e, que iso toma parte na formagio do corpo do $c^{\prime}$. plexo:

Algumas vezes es dols cromassomios que entram na formaçă do segriento comum as duas cruzes nao se unem, ou, se por acaso estiveram previamente unidos, desfazem a sua uniao, e o complexo se transforma em uma estrela de bicas desigiais, suportada por uma longa aste. (Figs. 3 e 4). Tanto uma corro oirtri dassas duas figuras, que sao as mais regularcs e caracteristicas das metáfases primárias, pode-se apresen- 
tar, em virtude de dobraduras e torgoes em seus ramos, mais ou menos defarmada.

Na pro-metáfase torna-se evidentemente mais dificll compreender a figura formada pelos sete cromossomias do compleż̃o. Im algutrias células, porém, ela se apresentia com a mesnia clareza com que se mostra has melhores metátases (Fig. 6).

\section{CISTOS THTRAPLOIDRS}

Alguns cistos tetraploides foram encontrados, cujas celulas exthlam sempre um grupo formado por 14 cromossomios reunidos de uma maneira que se neio deirava analisar e dois bivalentrs. que ora se encontravam separados. (FHg. 7), ora reunidos num conjunto tetravalente. (MIg. 8). Ium um dos individuos encontrou-se um cisto tetraplolde extremamente curioso, pois suas celulas mostravam, em todas as figuras que puderam ser analisadas, dois complexos independentes formadas por sete cromossomios cada um, tal como nas celulas diploides, e dois bivalentes livres. (Fig. 9):

\section{ESPERMATOCITOS SECUNDARIOB}

Nas metafases primárias o bivalente livre se orienta como de ordinário e os seus cromossomios se separam da maneira esperada, Incio um para cada polo. O complexo, formado pelos sete cromossomios restantes tambem se oriente de maneira regular. com todos os seus ramos no plano do equador. complexn sempre se desdobra em dols girupos, um de tres e outro de quatro cromossomios, que se dirigem para polos opostos. Pontes anafísicas duplas e cromossomios estirados entre o equador $\epsilon$ am dos polos sugerem a possibllidade de passarem para 0 mesnio lado, em consequencia de uma orientaça defeituosa, os dois elementos associados em um mesmo braco do complezo.

Dn regra cada polo recebe um membro do par independente e rres ou quatro elementos do grupo eptavalente. $O$ resultado é a divisto do espermatócito primário em dols espermatocitós secundários, um com quatro e outro com cinco cromassomlas. (F1g. 10 e 11). Asses cromossomios sto bastante curtos, podendo-se, porém, notar diferenças de tamanho. Comportamse como de ordinário. movendo-se para os polos encurvados para tles. 
Espermatócitos secundários com nove cromossomios foram raramente encrntrados, o que indica que algumas vezes os cromossomilos dos espermatocitos primários nåo conseguem separar-se. Outras variaçós numéricas parecem ocorrer, embora as observaçరes nesse particular năo tenham sido muito seguraf.

Espermatoroildes foram encontrados em grande numero, o que n'ostra que a espermiogenese se completa com regularidade.

Em geral as celulas de um mesmo cisto se encontram na mesma fase da meiose. Nos cinco machos de $\mathbf{S}$. Joaquim, porém, assinalave-se notável assincronismo, encontrando-be, muitas vezes, no mesmo cisto, espermatócitos primários e secundários em retafase.

\section{CROMOSSOMIOS SOMATICOS DA FEMEA}

Nas células foliculares do ovariútero inúmeras metáfases foram encontradas, cujos cromassomios puderam com segurança ser contados. Todas possuiam dez cromósscmios da mesına formu, alguns maiores e outros menores. (Fig. 12). As femeas possuem, pois, um cromossomios a mais com relaçăo aos machos

\section{MPRCANTSMO SEXXO-DETERMMNANTE}

A femea possuindo dez cromassomios nos tecidos somáticos deve produair ́́vulos de cinco. O macho é, como vimos, digametico, ou seja. produtor de espermatozoides com quatro e cum cinco cromossomios. Os primeiros serăo, pois, produtores de machos e os segundas de remeas.

\section{DISCUSSAO}

A parte mais importante deste trabalho é, sem dúvida, : demonstraçăo ta passibllidade de fixação de aberraçбes cro. mosscimicas em raças naturais.

A traça de $\mathrm{S}$. Joaquim næ̌o apresenta caráter algum que permità a sua distinça.o. Os 12 individuos (5 machos e 7 femeas) que forneceram o material para o presente estudo, examinacio: antes da disseraçáo, foram considerados como típicos Tityus bahieusis. Nenhuma particularidade de valor sistemático, pnr menor que fosse, póde ser descoberta. Isso nåo quer dizer que 
noo existam caracteres fisiologicos pelos quais ela possa ser distinguida. Em se tratando, porém, de uma especie selvagem apenas conhecicia da natureza e que jamais fol investigada do pontr de vista da sua biologia ou sequer criada em laboratório, năn passuimos outros dados, além dos morfológicos, para caracterizar a nova raça. E nesse particular ela so se distingue pelo namero e pela constituiçáo de seus cromossomios, sete dos quais se mostram formados por dols ou tres fragmentos de diferentes origens.

Nada sabemos a respeito da extensa desta raca. 0 que podemos afirm?r é que os 12 individuos provenientes da $\mathrm{Fa}$. zenda S. Tosé, ro municiplo de $\mathbf{S}$. Joaquim, a ela pertenciam.

Raças cromossomicas naturais conhecem-se em alguns Dip. teros, como por exemplo na Drosophila (v. DOBZHANSKY \& EPLING 1944) e na Sciara (v. CARSON 1944), devidas especi3lmente a inverstes de segmentos cromossomals e por conseguinte reconhecivels pelo exame das glandulas salivares. Afora os caracteres tirados da configuraçăo dos cromossomias glandula.res, nenhum outro existe, quer na morfologia, quer na fisiologia do orgarismo, que permita reconhecer as raças.

Os fatos em máo, relativos a Drosophila e a Sclara, mostram que as modificaçoes estruturais dos cromossomios náo exercem influencia alguma na morfologia do individuo, devendo porisso deser.penhar um papel bem insignificante como fonte de variaços hereditárias. Realmente, inversbes de todos os tamanhos, interessando a um ou mais cromossomios, translocaçరes, deficiencias, duplicaçóes, etc., năo conseguem mudar em nada as caracteristicas somáticas do organismo. A teoria dos "efeltos de posiçro" fics assim sèriamente abalada.

Os dados constantes do presentes trabalho são, a esse respeito, mais significativos, porque vem mostrar, que para a morfologia da espécte, tanto faz ela possuir os seus sels cromossomios normals em ambos os sexas, como possuir a femea dez e o macho nove, sei.e dus quals profundamente alterados.

Relativamente sexo-determinaçáo no Tityus de 8. Joaquim, estamos diante da curlosa ocorrencla de um mecanismo sezodeterminante em estado inciplente dentro de uma espećle monogamética em ambas os sexos. Na raça de S. Joaquim o macho tornou-se digamético e a sexo-determinaçáo passou a ser condiclonada nor um cromossomio especial. O macho possui apenas um cromossomios desse tipo e a femea dois. $O$ mais interessante, a araliar pelo que pode ser observado, é que o sexo-crumassomio encontra-se envolvido no complexo formado 
pelos sete e'ementos, sendo, provayelmente, um cromossomio constituicio por tragmentos de origem diferente.

No inicio dos meus estudos escorpionicos deparel com um caso isolado de anomalias cromossomicas, interpretado dife. rentemente, mar. que agora pode ser considerado como pertencendo á mesma natureza do descrito neste trabalho. (v. PIZA 1940). Tratava-se de um unico exemplar de Titjus bahiens's capturado na Escola, cujo testículo fora montado in toto no aceto-carmim. A proparaçăo, que nžo permitiu um estudo completo da aberraça, pois que algumas partes interessantes $r$ organ ticaram aglomeradas e pouco transparentes; serviu, co. tudo, para mostrar, que a condiçăo encontrada era a condiçăo de torlo 0 testiculo. Todos os espermatogonios em metáfase exibiam nove cromossomios, tal como hos machos de $\mathbf{S}$. Joaquim, sendo os espermatócitos primários providos de duas cruzes e um bastonete. Havendo quatro crqmossomios em cada cruz, nz̊o pude consilerar o bastonete, apesar de sua nitida bivalencla, cono tormando um par, o que daria um total de dez cromassémios, em desacordo com o número encontrado nos espermz.togonios. Fui, porisso, forçado a considera-lo como um univaler:e, cujos cromatidios se separavam, na anáfase, 20 mesino tempo qile os cromossomios envolvidos na formaçáo das cruzes. Encontrel metáfases primárias com as duas cruzes associadas, tal como no presente caso, havendo fotografado uma delas. (cf. PIZA, 1940, Fig. 24). Entretanto, embora tivesse notado algumas figuras em que havia um elemento que me pareceu pertencer di duas cruzes, nko cheguel a formar um jutzo correto $r$ respeito, supondo que as duas cruzes da figura, apesar do eonts io por um dos braços, fossem independentes. (cf. loc sit. pag. 146). Hoje estou convencido de que a Fig. 24 do citado trabalho representa duas cruzes ligadas por um elemento comum. formando um complexo de sete cromossomias, tendo ao lado um bivalente independente, tal como se observa no Titjus de S. Joaquim. A independencia das cruzes, como se ve na Fig. 23 daquele trabalho, deve significar uma desuniso secundária de dois dos trazmentos reunidos no cromossomio de ligaça.

\section{SUMMARY}

A na:ural cliromosomal race of Tityus bahiensts (scorpionns Buthitac) is described in the present paper. Five males and seven females received from St. Joaquim, State of S. Paulo, gave the following interesting results: 
All the spermatogonia of the five males were provided with 9 chromosomes of different slizes!

All primary spermatocytes showed at metaphase one independent bivilent of normal shape and a complex group formed by 7 chromasomes which have exchanged parts. Some of the chromosomes associnted in the complex group, to judge by their behavior, were composed of fragments of three different chromosomes, being thus paired with three other members of th: compound group. The manner in which all the 7 components of the group have paired with each other showed to be very .onstant. They gave always origin to a double-cross conflguration, the longst branch of which being formed by a long chromosome paired with two components of the group and with a third chromasome that did not belong to the group.

The chromnsomes of the independent bivalent separate regularly, goine to different poles. From the 7 elements of the compournid group, 4 go to one pole and 3 to the opposite one. Consequently, secondary spermatocytes with 4 and 5 chromosomes sire produced.

The females, so far as it can be inferred from the study of the follicilar cells of the ovariuterus, have 10 chromasomes. These females are, therefore, considered as being monogametic, that is, as producing eggs with 5 chromosomes. A sex-determining mechanism arose in this manner, the spermatiozoa with 5 chromoromes giving origin to females and those with 4 to :2ales. The fact that the sex chromosome is one of the elements taking part in the formation of the group, seems highly interesting to the author.

Tetraploid cysts have been occasionally found in the testjs. In one Individual the chromosomes of the tetraplold primary spermptorytes behaved as expected, forming a group of 14 elements. and two independent pairs or a tetravalent group In another individual, the chromosomes of the tetraplold cells have formed two independent groups of 7 ; and two independent pairs, as if both chromosomal sets were by their turn entirely independent frcm one another. This fact is certainly not devold of special interest.

The males as well as the females studied in this paper differed in nothing from the typical members of the species. The unique differential character of the new race is found in the umber and behavior of its chromosomes.

It is highly remarkable that the occurrences which have transformed the 6 chromosomes normally present in the specles into a new set of 9 elements, 7 of which have been profoun- 
dly altered in their structure, do not show any influence on the morphology of the organism. This fact, together with those found in the saliviary-chromosomes races of Drosophila and Sciara. compromises strongly the genetical concept of position effists.

\section{ITTERATURA CITADA}

CARSUN, H. L. 1944 - J. Morph. 72 : 11-59.

DOBZHANSKY, T. \& C. EPLING 1944 - Carnegle Inst. of Wastington Publ. 554.

FERN.4NDFS, A. 1946 - Bol. Soc. Broteriana, XX, 2.a Sér.: 93514.

PIZA. S. de Toledo, Jor 1939 - Scient. Gent. 1 : 255-261.

PIZA, S. de Toledo, Jor. 1939a - Jor, de Agron. 2 : 343-370.

PIZA. S. de Toledo, Jor. 1940 - Rev, de Biol. e Hyg. 10 : 143-155.

PIZA. S. de Toledo, Jor. 1941 - J. Hered. 32 : 423-426.

PIZA, S. de Toledo, Jor. 1943 - Rev. de Agric. $18:$ 249-276.

PIZA, S. de Toledo, Jor. $1943 a$ - Rev. de Agric. 18 : 455-457.

PIZA. S. de Toledo, Jor. 1943b - Amer. Nat. 77 : 442-462.

PIZA, S. de Toledo, Jor. 1944 - Rev. de Agric. 19 : 133-147.

PIZA. S. de Toledo, Jor. 1946 - An. Esc. Sup. Agric. "Luin de Queiros 3 : 340-346.

PIZA S. de Toledo, Jor. 1947 - An. Esc. Sup. Agric. "Luik de Queiros" 4: 169-176.

PIZA, S. de Toledo, Jor. 1947a - An. Esc. Sup. Agric. "Luiz de Queiroz" 4 : 177-182. 


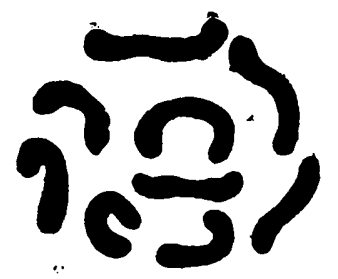

Fig. 1 - Metáfase do espermatogônio, com 9 cromossômios (x 3750)
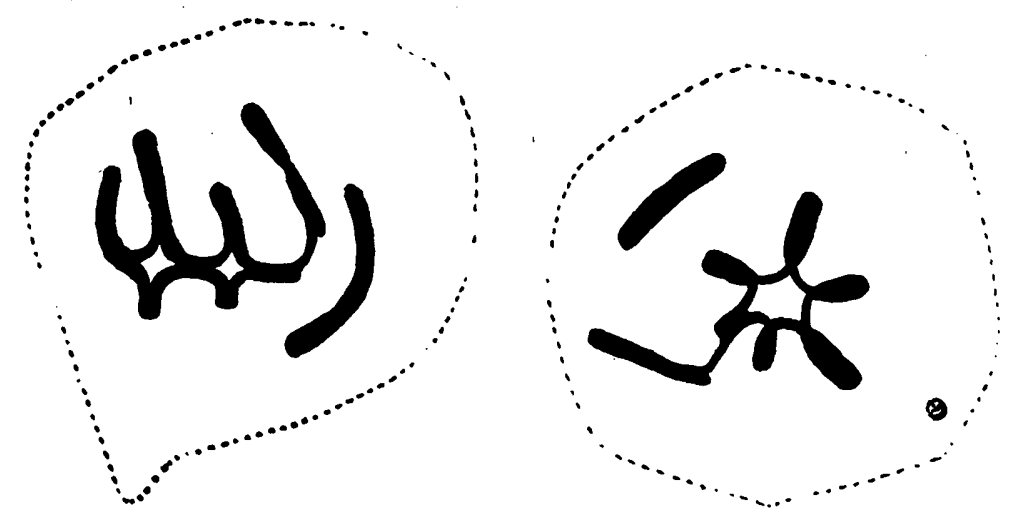

Figs. : c : L L'as metáfases primárias mostrando um bivalente livre e um grupo formado por sete cromossômios

(x 3750)
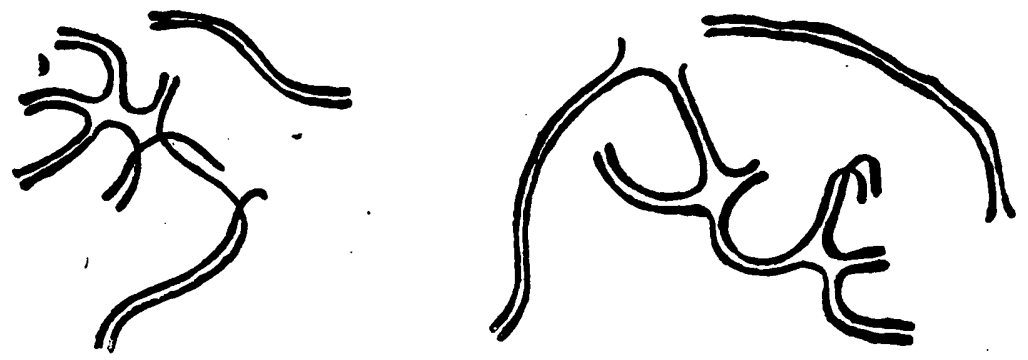

Figs. \& e 5 - Metáfase e pro-metáfase dos espermatócitos primárioz em scrio-',rce isa, vencio-se claramente o modo de pareamento dos cromossômios 


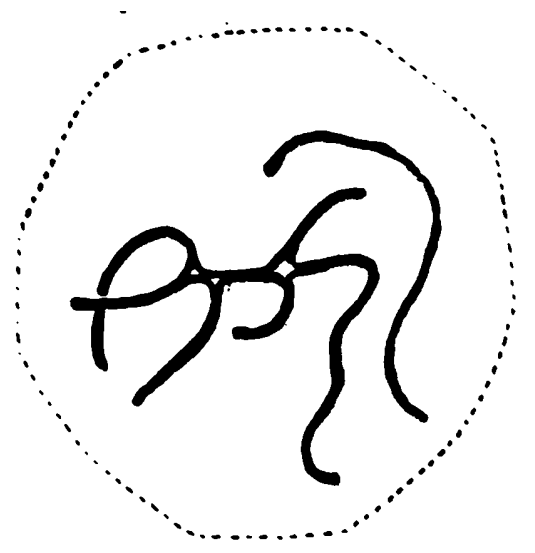

Fis. 6 - Pro-metafase primária (x Sroo)
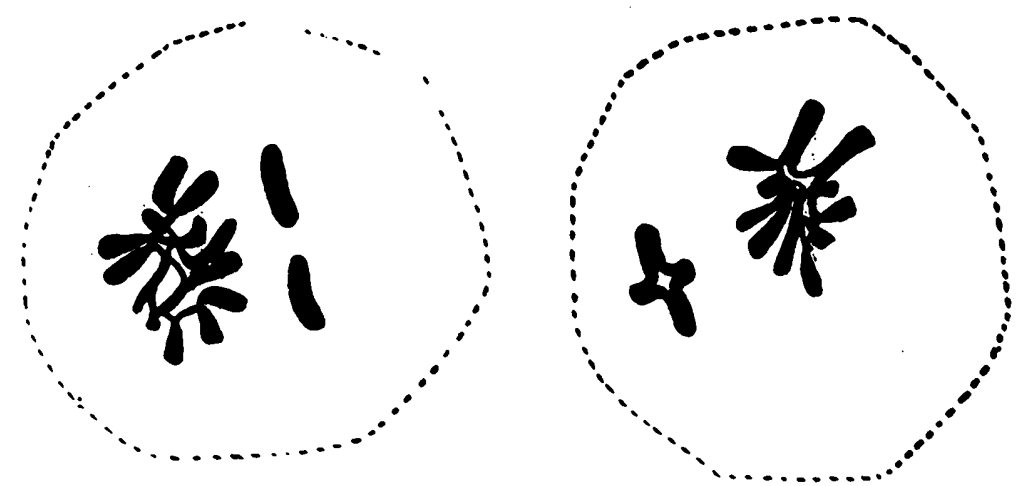

Figss. 7 e 8 - Metafases primárias tetraplbides com um grupo de 14 cromassómios e 2 bivalentes livres (Fig. 7) ou reunidos num grupo tetravalonte (Fig. 8)

( 2000$)$ 
Fig. 9 -- Espermatócito primário tetraploide com dois grupos independentes de sete cromossômios e dois bivalentes igualmente independentes.

(x 2500)
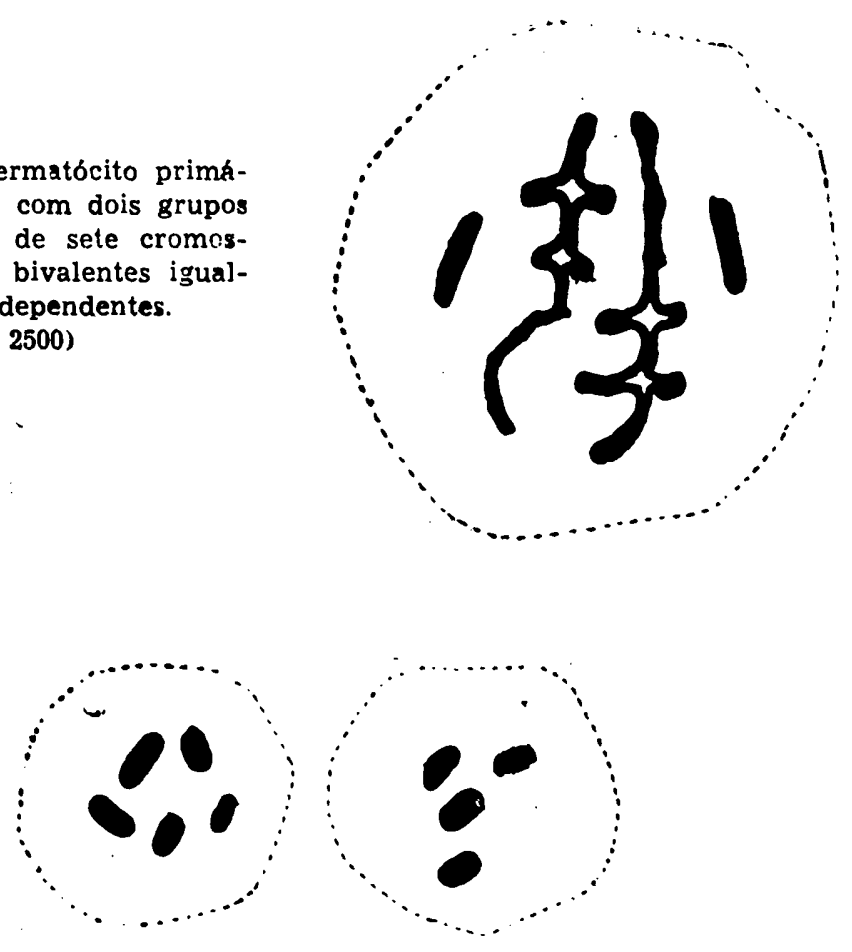

Figs. 10 e 11 - Espermatócitos secundários com 5 e com 4 cromossômios.

(x 2500)

Fig. 12 - Célula folicular do ovariútero em metáfase, com 10 cromossómios)

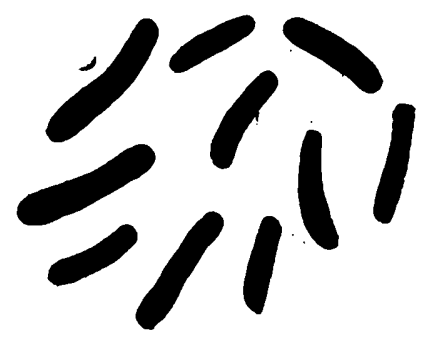

